
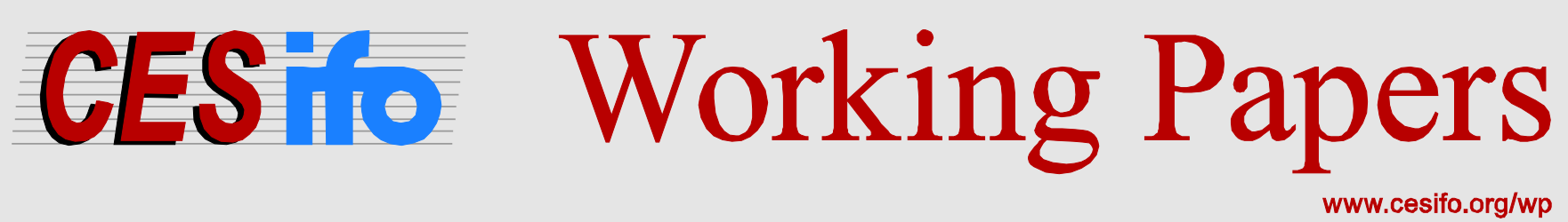

\title{
Stakeholder Governance, Competition and Firm Value
}

\author{
Franklin Allen \\ Elena Carletti \\ Robert Marquez
}

CESIFO WORKING PAPER NO. 4652

CATEGORY 11: INDUSTRIAL ORGANISATION

FEBRUARY 2014

An electronic version of the paper may be downloaded

- from the SSRN website:

- from the RePEc website:

- from the CESifo website:

WWW.SSRN.com

www.RePEc.org

www.CESifo-group.org/wp

\section{CESifo}




\title{
Stakeholder Governance, Competition and Firm Value
}

\begin{abstract}
In many countries, the legal system or social norms ensure that firms are stakeholder oriented. We analyze the advantages and disadvantages of stakeholder-oriented firms that are concerned with employees and suppliers compared to shareholder-oriented firms in a model of imperfect competition. Stakeholder firms are more (less) valuable than shareholder firms when marginal cost uncertainty is greater (less) than demand uncertainty. With globalization shareholder firms and stakeholder firms often compete. We identify the circumstances where stakeholder firms are more valuable than shareholder firms and compare these mixed equilibria with the pure equilibria with stakeholder and shareholder firms only. Finally, we analyze firm financial constraints and derive implications for the capital structure of stakeholder firms.
\end{abstract}

JEL-Code: G320, L210, L220.

\author{
Franklin Allen \\ Wharton School \\ University of Pennsylvania \\ 3620 Locust Walk, Room 2314 \\ USA - Philadelphia, PA 19104-6367 \\ allenf@wharton.upenn.edu
}

\author{
Elena Carletti \\ Bocconi University \\ Department of Finance \\ Grafton Building / Via Roentgen 1 \\ Italy - 20136 Milan \\ elena.carletti@unibocconi.it
}

\author{
Robert Marquez \\ University of California, Davis \\ 3410 Gallagher Hall, One Shields Avenue \\ USA - Davis, CA 95616 \\ rsmarquez@ucdavis.edu
}

August 2, 2013

We are grateful to the editor Marco Pagano and two anonymous referees for very helpful comments and suggestions. We also wish to thank Anat Admati, Gianni De Nicolo, Mariassunta Giannetti, Peter Gourevitch, John Graham, Campbell Harvey, Kose John, Eugene Kandel, Steven Ongena, Giancarlo Spagnolo, Merih Sevilir, Raghu Sundaram, Kenichi Ueda and Michael Weisbach for their comments and seminar participants at ASU, Berkeley (Haas), Stanford (GSB), HEC, the Universities of Frankfurt, Gothenberg, Mannheim, the Max Planck Institute in Bonn, and to participants at the 2008 FIRS (Alaska) Conference, the UNC-Duke 2006 Corporate Finance Conference, the 2006 Summer Research Conference at the Indian School of Business, and the 2007 NBER/RFS Workshop. We gratefully acknowledge financial support from the Pierre Werner Chair Programme on Monetary Unions at the European University Institute. Franklin Allen is also grateful to the Wharton Financial Institutions Center for financial support. 


\section{Introduction}

In their classic survey of corporate governance, Shleifer and Vishny (1997; p. 738) outline their focus in the following way: "Our perspective on corporate governance is a straightforward agency perspective, sometimes referred to as separation of ownership and control. We want to know how investors get the managers to give them back their money." In the US and UK and many other Anglo-Saxon countries there is wide agreement that this is what corporate governance is about. The law is clear that shareholders are the owners of the firm and managers have a fiduciary (i.e., very strong) duty to act in their interests. ${ }^{1}$ Most of the academic literature on governance has taken this perspective (see, e.g., Becht, Bolton, and Röell, 2003, for a more recent survey).

However, moving beyond the cases of the US and the UK, firms' objectives vary by country and often deviate significantly from the paradigm of shareholder value maximization. As Denis and McConnell (2003; p. 6) point out in their survey of international corporate governance: "in many European countries shareholder wealth maximization has not been the only - or even necessarily the primary - goal of the board of directors." In Germany, for example, large firms are legally required to pursue the interests of parties beyond just shareholders through the system of co-determination in which employees and shareholders in large corporations have an equal number of seats on the supervisory board of the company (see Rieckers and Spindler, 2004, and Schmidt, 2004).

Germany is by no means the only country where the interests of parties other than just shareholders have bearing on companies' policies. Employees are represented - directly or indirectly - in companies' boards in several other countries such as Austria, the Netherlands, Denmark, Sweden, Luxembourg and France (Wymeersch, 1998, and Ginglinger, Megginson, and Waxin, 2009). Similar arrangements are present in China, where firms are explicitly required to bear in mind their social responsibilities in conducting their business operations

\footnotetext{
${ }^{1}$ This holds except when the corporation is near insolvency or is insolvent in which case the managers have duties to creditors and other stakeholders - see Campbell and Frost (2007).
} 
(Wang and Huang, 2006). In Japan social norms have similar effects in that it is widely accepted that stakeholder interests, and in particular employee interests, play a predominant role (Dore, 2000, Jackson and Miyajima, 2007, and Milhaupt 2001).

The common theme among these different regimes can be seen from surveys of managers reported in Yoshimori (1995). Figure 1 shows the choices of senior managers at a sample of major corporations in Japan, Germany, France, the US, and the UK, between the following two alternatives:

(a) A company exists for the interest of all stakeholders (dark bar).

(b) Shareholder interest should be given the first priority (light bar).

In Japan the overwhelming response by $97 \%$ of the managers was that all stakeholders were important. Similarly, in Germany and France, $83 \%$ and $78 \%$, respectively, viewed the firm as being for all stakeholders. At the other end of the spectrum, managers in the US and the UK, by majorities of $76 \%$ and $71 \%$ respectively, stated that shareholders' interests should be given priority. The same survey also asked the managers what their priorities were with regard to employee layoffs. The answers show that, at least for Japan, Germany and France, firm continuity and employment preservation are important concerns. In many countries, therefore, the legal system or social convention have as a common objective the inclusion of parties beyond shareholders into firms' decision-making processes. In particular, workers are seen as important stakeholders in the firm, with continuity of employment being an important objective.

The current literature on corporate governance does not address these issues. In most papers, since at least Jensen and Meckling (1976), the focus is on how to resolve agency issues concerning managers or employees so as to maximize shareholder value. Sometimes this involves including employees in the governance process to provide good incentives and increase firm value (e.g., Jensen, 2001). However, when stakeholder governance is imposed by law or social norm, a firm's objective function incorporates the interests of both shareholders and other stakeholders. The purpose of this paper is to address these issues and provide an 
understanding of how imposing stakeholder governance affects firms' behavior even when this involves a trade-off between the interests of shareholders and those of other stakeholders. Our main idea is that stakeholder firms internalize the effects of their behavior on stakeholders other than shareholders. In particular, they are concerned with the non-pecuniary benefits that their stakeholders would lose should the firm not survive. As a consequence, stakeholder firms are more concerned with avoiding bankruptcy since this prevents their stakeholders from enjoying their benefits. This approach of modelling stakeholder firms is in line with Tirole (2006), who discusses the possibility of including the surpluses of all stakeholders in the firm's objective function. The value placed on survival by stakeholder firms finds also empirical support. ${ }^{2}$

We start by considering a standard two-period duopoly model with imperfect price competition where firms maximize shareholder value. In the first period firms are subject to a random shock, which can stem from two different sources of uncertainty: 1) shocks to the firms' marginal production costs; and 2) shocks to the firms' realized demand for their products. If these shocks are large enough the firms may be unable to continue operating. In choosing their first period prices, firms take into account the effects on first period profits as well as on the probability of surviving into the second period.

We first characterize how the different sources of uncertainty influence firms' product market decisions. When firms are uncertain as to what their realized costs will be, they have an incentive to keep prices high in order to reduce the likelihood that they will be unable to cover their actual costs. By contrast, when firms face demand uncertainty they prefer to err on the side of lower prices so as to assure themselves of having at least some sales.

We then introduce stakeholder governance by assuming that firms in stakeholder oriented societies are more concerned about survival than firms in shareholder oriented societies.

\footnotetext{
${ }^{2}$ Verwijmeren and Derwall (2010) find that firms with leading track records in employee well-being have a significant lower probability of bankruptcy. Similarly, authors' estimates (see Table 1) confirm that firms in Germany, France and Japan have significantly lower probabilities of bankruptcy than firms in the US, as measured by the Black-Sholes-Merton model (we are grateful to Gianni De Nicolo for the data and calculations related to this result and to Steven Ongena for the preparation of the table).
} 
Interestingly, we find that a concern for stakeholders can magnify the effect of uncertainty. When firms face cost uncertainty, stakeholder governance leads to a further softening of competition: firms charge higher prices and their probability of surviving increases, thus benefitting stakeholders. But the shareholders can also be better off through the strategic benefit of softening competition which increases firm value. By contrast, when demand is uncertain, firms reduce prices even further when they are concerned about stakeholders. This increases the firm's probability of survival and benefits stakeholders, but since it increases competition it reduces overall firm value and hurts shareholders. For this case, therefore, the interests of stakeholders and those of shareholders are not aligned, and having stakeholder governance reduces shareholder value. Therefore, the effect on shareholders of having a stakeholder-oriented governance structure very much depends on the type of uncertainty firms face. ${ }^{3}$

We then consider the case of globalization, where it has become commonplace for firms from shareholder societies to compete with firms from stakeholder societies. We show that all firms stand to benefit from the stakeholder orientation of just one of them when the primary uncertainty firms face is about their costs. We also compare firm value across regimes, contrasting these mixed equilibria under globalization with equilibria where all firms are either shareholder or stakeholder oriented. We again establish that a stakeholder orientation can benefit shareholders in the case of cost uncertainty. The results have interesting implications for the political economy of foreign entry.

Finally, we extend the basic model in various direction. We first consider different shock structures. Then, we introduce financial constraints and derive interesting implications concerning the capital structure of stakeholder firms. Lastly, we consider various specifications concerning firm continuation profits in the second period and the possibility of firm exit.

Our paper is related to a number of strands of literature. The first is concerned with firms'

\footnotetext{
${ }^{3}$ The result that stakeholder governance may increase firm value is related to Veblen's argument, as reported in Demsetz (1983), that the separation of ownership and control may be desirable as it transfers control from profit-maximizing owners to efficiency-seeking managers.
} 
objective functions. Blinder (1993) models the objective function of Japanese firms as the weighted sum of shareholder profits and a function of employee earnings and shows that this leads firms to maximize revenue. In contrast, we put the firm-specific benefits stakeholders receive in the firm's objective function and show that the concern for stakeholders softens or hardens competition depending on the kind of uncertainty firms face. Acharya, Myers, and Rajan (2011) also analyze the effect of stakeholders on firm continuity. However, whereas they focus on the role of critical, younger employees in the internal operation of the firm and its continuity, we are interested in the effects of concerns for continuity on market equilibrium.

Our emphasis on product market competition links our analysis to several papers in industrial organization. Sklivas (1987) shows that in oligopolistic industries shareholders can choose managerial incentives to alter the way in which firms compete and shows that firm value can be affected in this way. Fershtman and Judd (1987) also consider the interaction between managerial incentives and competition in oligopolistic markets. They show that compensation contracts can optimally depend on things other than profits such as sales. In a similar spirit, Aggarwal and Samwick (1999) use a framework of imperfectly competitive product markets to explain the optimality of compensation contracts for managers based on both own and rival performance. Furthermore, there is a large literature, starting with Brander and Lewis (1986), Maksimovic and Titman (1991), Showalter (1995), and more recently Dasgupta and Titman (1998), showing that debt acts as a precommitment device that changes the way in which firms compete (Allen, 2000, contains a discussion of this literature). Our approach is related in that stakeholder governance has product market implications. These implications are however, independent from those stemming from capital structure considerations.

A number of papers have been concerned with the normative issue of whether it is socially desirable for firms to pursue anything other than shareholder interests. Tirole (2001, 2006) takes a negative view on the desirability of adopting a stakeholder-oriented objective for the firm given the difficulty to measure stakeholder welfare and thus to charge managers with 
anything other than maximization of firm value. Allen and Gale (2000, Chapter 12) and Allen (2005) take a more optimistic view arguing that changing firms' objective functions from just focusing on shareholder wealth can correct for market failures and provide a Pareto improvement in welfare. In contrast to these papers, our focus is positive in that we are concerned with the likely effects of the stakeholder governance that is required in many countries.

In a recent contribution, Magill, Quinzii and Rochet (2010) develop a model of stakeholder firms that addresses the concerns raised by Tirole (2001). They model firms' investment choices as affecting the probability distributions of outputs and show that shareholder firms do not lead to Pareto optimality because there are externalities on consumers and employees. However, if consumers and employees have marketable property rights on these externalities, having firms maximize stakeholder value improves social welfare. Our paper is related but focuses on a different externality which arises because shareholder-oriented firms do not internalize the impact of the firm's survival on the continuation payoffs of consumers and employees, whereas a stakeholder-oriented firm does.

The paper is also related to the literature on corporate governance and stakeholder protection. Pagano and Volpin (2005) argue that stakeholder orientation in the form of longterm labor contracts discourages hostile takeovers, thus benefitting inefficient managers. By contrast, Cespa and Cestone (2007) argue that explicit stakeholder protection can increase managerial turnover and firm value as it reduces entrenchment of inefficient CEOs. As in these papers, in our paper stakeholder orientation can be beneficial or detrimental to firm value. However, we view it as a way to commit managers to focus more on firm survival and act accordingly rather than as a way of benefitting or discouraging inefficient management.

The remainder of the paper proceeds as follows. Section 2 presents a model analyzing the effects in terms of price competition and firm value of having firms that care about other stakeholders in addition to shareholders. Section 3 looks at globalization where different types of firms compete with each other. Section 4 analyzes a number of extensions, and 
Section 5 presents the empirical implications of our analysis. Section 6 concludes.

\section{Models of Governance}

In this section we develop a simple model where different forms of governance are associated with different objective functions for the firms. We start with the standard case where firms maximize shareholder value. We then analyze how a concern for stakeholders affects the way firms compete.

\subsection{Shareholder firms}

Consider first a simple one-period model where two firms, $i \in\{1,2\}$, offer differentiated products and compete in prices. Each firm $i$ faces a demand curve given by

$$
D_{i}=A-b p_{i}+d p_{j}
$$

for $i \neq j$, where $p_{i}$ and $p_{j}$ are the prices charged by firms $i$ and $j$, respectively, and $b$ and $d$ depend on consumers' preferences over the good sold by firm $i$ relative to that sold by firm $j$. We assume throughout that $b \geq d$, so that firm $i$ 's demand is at least as sensitive to its own price as it is to the price charged by its competitor. Each firm $i$ chooses its price to maximize profit as given by

$$
\max _{p_{i}} \pi_{i}=\max _{p_{i}}\left(p_{i}-c\right) D_{i}=\max _{p_{i}}\left(p_{i}-c\right)\left(A-b p_{i}+d p_{j}\right)
$$

where $c$ represents the marginal cost of producing one unit of output, and is the same for both firms. The first order condition for profit maximization gives

$$
\left(A-b p_{i}+d p_{j}\right)-\left(p_{i}-c\right) b=0
$$


which yields the reaction function

$$
p_{i}=\frac{A+b c}{2 b}+\frac{d}{2 b} p_{j}
$$

Given a similar expression for firm $j$, we can solve for the symmetric equilibrium prices $\widehat{p}$ to obtain:

$$
\widehat{p}=\frac{A+b c}{2 b-d} .
$$

In order to ensure that profits are positive, we assume that $\widehat{p}>c$. A sufficient condition for this is that $A-c(b-d)>0$.

We now enrich this basic model by introducing a second period identical to the first. We also assume that each firm $i$ is subject to various forms of uncertainty which may affect its first period pricing decisions. Specifically, we consider two distinct cases, one where each firm is subject to a shock to its marginal cost in period 1 , so that $\widetilde{c}_{i}=c+\widetilde{\epsilon}_{i}$, where $\widetilde{\epsilon}_{i}$ is distributed uniformly on the interval $[-\epsilon, \epsilon]$. The second case we consider is where each firm faces an uncertain demand, so that $\widetilde{D}_{i}=D_{i}-\widetilde{\eta}_{i}=A-b p_{i 1}+d p_{j 1}-\widetilde{\eta}_{i}$, where $\widetilde{\eta}_{i}$ is distributed uniformly on the interval $[-\eta, \eta] .{ }^{4}$ For either case, we assume that firm $i$ can operate in period 2 only if its profit in the first period, $\pi_{i 1}$, is nonnegative or, equivalently, if the respective shock is not too large. ${ }^{5}$ For the case of marginal cost uncertainty, $\pi_{i 1} \geq 0 \Leftrightarrow \widetilde{\epsilon}_{i} \leq p_{i 1}-c$, so that the realized shock does not exceed the firm's markup over its expected marginal cost. For the case of demand uncertainty, $\pi_{i 1} \geq 0 \Leftrightarrow \widetilde{D}_{i} \geq 0$, which is equivalent to $\widetilde{\eta}_{i} \leq A-b p_{i 1}+d p_{j 1}$, so that the shock to demand is lower than the firm's expected demand. We analyze the two cases of uncertainty in turn below.

Marginal cost uncertainty. Firm $i$ 's problem is to choose the price that maximizes its

\footnotetext{
${ }^{4}$ We consider alternative shock structures below in Section 4.1.

${ }^{5}$ In Section 4.2 we explicitly consider firm capital structure and analyze the case where firm $i$ goes bankrupt when its first period profit is insufficient to fulfill its debt obligation, and show that the results are qualitatively similar to the case considered here where the firm fails if its profits are not positive.
} 
overall market value, $V_{i}$, as given by

$$
\max _{p_{i 1}} V_{i}=E\left[\pi_{i 1}\right]+\operatorname{Pr}\left(\widetilde{\epsilon}_{i} \leq p_{i 1}-c\right) \pi_{2}
$$

The first term represents the expected profit in the first period, while the second term is what firm $i$ obtains in expectation in the second period if it survives. For simplicity, this equals $\pi_{2}$ irrespective of whether only firm $i$ survives or both firms do. ${ }^{6}$ The firm can also fail, in which case it earns zero profits. Noting that $E\left[\pi_{i 1}\right]=\left(p_{i 1}-c\right) D_{i}$ and $\operatorname{Pr}\left(\widetilde{\epsilon}_{i} \leq p_{i 1}-c\right)=\frac{p_{i 1}-c+\epsilon}{2 \epsilon}$, the maximization problem can be written as

$$
\max _{p_{i 1}} V_{i}=\left(p_{i 1}-c\right) D_{i}+\frac{p_{i 1}-c+\epsilon}{2 \epsilon} \pi_{2}
$$

The first-order condition for this problem is

$$
\frac{\partial V_{i}}{\partial p_{i 1}}=\left(A-b p_{i 1}+d p_{j 1}\right)-b\left(p_{i 1}-c\right)+\frac{1}{2 \epsilon} \pi_{2}=0
$$

The first two terms represent the total marginal effect of a change in $p_{i 1}$ on the expected first-period profit. The last term captures the effect of a change in $p_{i 1}$ on the second-period profit of firm $i$ through the marginal change in its survival probability, $\frac{1}{2 \epsilon}$. As is normally the case in models of imperfect competition, prices are strategic complements in our framework. This can be seen from the condition $\frac{\partial^{2} V_{i}}{\partial p_{i 1} \partial p_{j 1}}=d>0$, which also guarantees that the standard regularity condition (see Dixit, 1986) that $\left|\frac{\partial^{2} V_{i} / \partial p_{i 1} \partial p_{j 1}}{\partial^{2} V_{i} / \partial p_{i 1}^{2}}\right|<1$ is always satisfied.

Solving (3) for $p_{i 1}$ and then setting $p_{i 1}=p_{j 1}$, we can find the unique symmetric equilibrium price as

$$
\widehat{p}_{1}^{C}=\frac{A+b c+\pi_{2} / 2 \epsilon}{2 b-d}
$$

where the superscript $C$ indicates the case of marginal cost uncertainty. We assume that the magnitude of $\epsilon$ is such that $\widehat{p}_{1}^{C}$ lies in the interior of the interval for costs. If we compare $\widehat{p}_{1}^{C}$

\footnotetext{
${ }^{6}$ We extend the analysis to different continuation payoffs in Section 4.3.
} 
with the one-period price $\widehat{p}$ we obtain that

$$
\widehat{p}_{1}^{C}-\widehat{p}=\frac{\pi_{2}}{2 \epsilon(2 b-d)}>0
$$

The intuition for this result is that when firms care about surviving until period 2, they maximize their expected profits across both periods. Firms set higher first period prices than in the one-period model in order to increase their probability of survival, $\operatorname{Pr}\left(\widetilde{\epsilon}_{i} \leq p_{i 1}-c\right)$. In other words, the concern for survival softens competition and, by raising prices, also reduces output.

Demand uncertainty: Similarly to before, firm $i$ 's problem is to choose the first period price that maximizes its market value, given by

$$
\max _{p_{i 1}} V_{i}=E\left[\pi_{i 1}\right]+\operatorname{Pr}\left(\widetilde{\eta}_{i} \leq A-b p_{i 1}+d p_{j 1}\right) \pi_{2}
$$

Since $E\left[\pi_{i 1}\right]=\left(p_{i 1}-c\right) D_{i}$ and $\operatorname{Pr}\left(\widetilde{\eta}_{i} \leq A-b p_{i 1}+d p_{j 1}\right)=\frac{A-b p_{i 1}+d p_{j 1}+\eta}{2 \eta}$, this maximization problem can be written as

$$
\max _{p_{i 1}} V_{i}=\left(p_{i 1}-c\right) D_{i}+\frac{A-b p_{i 1}+d p_{j 1}+\eta}{2 \eta} \pi_{2}
$$

The first order condition to this problem is given by

$$
\frac{\partial V_{i}}{\partial p_{i 1}}=A-b p_{i 1}+d p_{j 1}-b\left(p_{i 1}-c\right)-\frac{b}{2 \eta} \pi_{2}=0
$$

As before, we can solve this expression to obtain the reaction function for firm $i$ and then setting $p_{i 1}=p_{j 1}$, we can find the unique symmetric equilibrium price as

$$
\widehat{p}_{1}^{D}=\frac{A+b c-b \pi_{2} / 2 \eta}{2 b-d}
$$

where the superscript $D$ denotes the case of demand uncertainty. Note that, in contrast 
to the case where firms have uncertain marginal production costs, the optimal price is now lower than the single period optimum, $\widehat{p}$ :

$$
\widehat{p}_{1}^{D}-\widehat{p}=-\frac{b \pi_{2}}{2 \eta(2 b-d)}<0
$$

The intuition for this result is that, when a firm faces uncertain demand, posting too high a price risks losing all sales if demand turns out to be significantly lower than expected. In order to increase the chance of having actual sales, and therefore of earning some profit and being able to operate in the second period, the firm finds it optimal to reduce its price relative to the equilibrium price in the single-period setting. In contrast to the case with marginal cost uncertainty, competition is then intensified since each firm has an incentive to reduce its price in order to generate sufficient demand. In equilibrium, firms charge lower prices and, as a consequence, increase expected output.

\subsection{Stakeholder firms}

So far we have considered the case where firms maximize only shareholder value. However, as discussed above, in many countries like Germany, Japan and France, the legal system and social environment are such that firms also consider the interests of other stakeholders, such as workers or suppliers, in adopting strategic decisions. To capture this in our model, we modify the firm's objective function so that the interests of stakeholders like employees and suppliers are represented in the firm's decision making process. In particular, we suppose that stakeholders internalize the benefit stemming from the continuation of the firm. The idea is that, if the firm survives, these stakeholders do not have to bear any of the (possibly nonpecuniary) costs associated with the failure of a firm in terms, for example, of having to 
find new jobs and customers. In this case, the objective function for firm $i$ becomes:

$$
\begin{aligned}
\max _{p_{i 1}} \Omega_{i} & =V_{i}+\operatorname{Pr}\left(\pi_{i 1} \geq 0\right) K_{i} \\
& =E\left[\pi_{i 1}\right]+\operatorname{Pr}\left(\pi_{i 1} \geq 0\right)\left(\pi_{2}+K_{i}\right),
\end{aligned}
$$

where $K_{i}$ is the part of the stakeholders' benefits in case of firm survival. Since this is determined by the legal and social environment it is the same for all firms so that $K_{i}=$ $K_{j}=K$.

We obtain the following result.

Proposition 1 (a) With marginal cost uncertainty, stakeholder firms set higher prices than shareholder firms, i.e., $\widehat{p}_{1 K}^{C}=\widehat{p}_{1}^{C}+\frac{1}{2 \epsilon(2 b-d)} K$. (b) With demand uncertainty, stakeholder firms set lower prices than shareholder firms, i.e., $\widehat{p}_{1 K}^{D}=\widehat{p}_{1}^{D}-\frac{b}{2 \eta(2 b-d)} K$.

Proposition 1 can be easily derived by solving (7) for the optimal first-period price. The proposition establishes that with marginal cost uncertainty a concern for stakeholders serves to soften competition relative to the case of shareholder firms by increasing prices and reducing quantity in the first period, while the opposite holds in the case of demand uncertainty. The intuition is simple. As stakeholder firms care more about surviving than shareholder firms, in the case of marginal cost uncertainty they charge higher prices to guarantee a higher probability of survival. This implies that in this case firms' production in stakeholder societies is further away from the efficiency benchmark provided by the perfect competition paradigm. By contrast, in the case of demand uncertainty a concern for stakeholders leads to a further decrease in first period prices relative to the case of shareholder-oriented firms. This occurs because with demand uncertainty stakeholder firms charge lower prices so as to ensure a positive level of demand for their products. Clearly, this increases competition and raises expected output while lowering firms' markups.

An implication of Proposition 1 is that, since $b>d$, the equilibrium price is increasing in the concern for stakeholder, as modeled as an increase in the parameter $K$, with marginal 
cost uncertainty and decreasing in $K$ with demand uncertainty.

\subsection{Firm Value}

We can now turn to the comparison of the firms' values under the two governance structures. To do so, we separate the two sources of uncertainty again in order to clearly identify their different effects.

Marginal cost uncertainty: We start with the value of a shareholder firm. Substituting the equilibrium symmetric price $\widehat{p}_{1}^{C}$ as in (4) for both $p_{i 1}$ and $p_{j 1}$ into (2) and rearranging the terms, we obtain the following expression for the equilibrium value of a shareholder firm:

$$
\widehat{V}_{S H A}^{C}=-A c-\frac{(c-\epsilon)}{2 \epsilon} \pi_{2}+\left[A+c(b-d)+\frac{\pi_{2}}{2 \epsilon}\right] \widehat{p}_{1}^{C}-(b-d)\left(\widehat{p}_{1}^{C}\right)^{2}
$$

We note that $\widehat{V}_{S H A}^{C}$ is concave in the equilibrium price $\widehat{p}_{1}^{C}$.

Similarly, by substituting $\widehat{p}_{1 K}^{C}$ as in Proposition 1 for both $p_{i 1}$ and $p_{j 1}$ into (2), we obtain an expression for the equilibrium value of a stakeholder firm that faces uncertainty concerning its marginal costs as a quadratic function of $K$ :

$$
\widehat{V}_{S T A}^{C}(K)=\widehat{V}_{S H A}^{C}+\frac{d\left[A+c(b-d)+\pi_{2} / 2 \epsilon\right]}{2 \epsilon(2 b-d)^{2}} K-\frac{(b-d)}{4 \epsilon^{2}(2 b-d)^{2}} K^{2} .
$$

Demand uncertainty: Following the same approach as above, we can substitute the equilibrium price $\widehat{p}_{1}^{D}$ from (6) into (5) to obtain

$$
\widehat{V}_{S H A}^{D}=-A c+\frac{A+\eta}{2 \eta} \pi_{2}+\left[A+(b-d)\left(c-\frac{\pi_{2}}{2 \eta}\right)\right] \widehat{p}_{1}^{D}-(b-d)\left(\widehat{p}_{1}^{D}\right)^{2} .
$$

Likewise, we can instead substitute $\widehat{p}_{1 K}^{D}$ as in Proposition 1 into (2) to obtain the equilibrium value of a stakeholder oriented firm. After some manipulation, we obtain

$$
\widehat{V}_{S T A}^{D}(K)=\widehat{V}_{S H A}^{D}-\frac{b d\left[A+(b-d)\left(c-\pi_{2} / 2 \eta\right)\right]}{2 \eta(2 b-d)^{2}} K-\frac{b^{2}(b-d)}{4 \eta^{2}(2 b-d)^{2}} K^{2} .
$$


We can now state the following proposition, which summarizes the effect of a stakeholder orientation on overall firm (i.e., shareholder) value.

Proposition 2 (a) With marginal cost uncertainty, stakeholder firms have higher value than shareholder firms if $0<K<K^{*}$ where $K^{*}=\frac{2 \epsilon d\left[A-c(b-d)+\pi_{2} / 2 \epsilon\right]}{(b-d)}$ satisfies $\widehat{V}_{S H A}^{C}=\widehat{V}_{S T A}^{C}\left(K^{*}\right)$; while they have a lower value if $K>K^{*}$. (b) With demand uncertainty, stakeholder firms always have lower value than shareholder firms.

Proposition 2 establishes that whether a stakeholder orientation results in an increase or a fall in the value of the firm compared to a shareholder orientation depends on the type of uncertainty that firms face. In particular, firms in stakeholder-oriented economies can have a higher overall value than those in shareholder-oriented economies when firms are uncertain about their marginal costs, but not when the primary source of uncertainty concerns the demand for their product.

These results are established directly from inspection of (9) and (11). Part (a) of the proposition is illustrated in Figure 2. Since $b>d$ and $A-c(b-d)>0, \widehat{V}_{S T A}^{C}(K)$ is a concave function of $K$ and has a positive slope at $K=0$; while $\widehat{V}_{S H A}^{C}$ is, by definition, constant with respect to $K$. As the graph shows, firms in a stakeholder society are more valuable than firms in a shareholder society for $0<K<K^{*}$.

Part (b) of the proposition follows from similar arguments. The function $\widehat{V}_{S T A}^{D}(K)$ is also a concave function of $K$ but its slope at $K=0$ is negative since $A-c(b-d)>0$. It follows immediately that in this case having a stakeholder orientation always leads to a reduction in firm value.

The result in Proposition 2 implies that with marginal cost uncertainty shareholders' and stakeholders' interests can be aligned. The higher prices induced by the firm's stakeholder orientation benefits the shareholders in terms of higher overall profits and the stakeholders in terms of higher probability of survival. However, when the firms' stakeholder orientation is too large (i.e., when $K$ is too big) being stakeholder oriented decreases firm value since 
it forces firms to focus too much on survival at the cost of losing profitability and market value. Similarly, when firms are more concerned about the overall demand for their product, a stakeholder orientation leads to lower firm value as it reduces prices and increases competition.

\section{Globalization: Competition between Shareholder and Stakeholder Firms}

So far we have considered the case where all firms operate in the same legal environment and are thus symmetric. We now consider a setting where firms of different types compete together. This kind of competition may occur as a result of globalization where firms from shareholder societies (such as the US) compete with those in countries where some measure of stakeholder governance is mandated by law or social norms (such as Germany). The results have interesting implications in terms of the ease with which firms enter into new markets through acquisitions. For brevity, we restrict the analysis to the case of marginal cost uncertainty. The case with demand uncertainty can be analyzed similarly.

We adopt the convention that firm $i$ is the shareholder firm and firm $j$ is the stakeholder firm so that $K_{i}=0$ and $K_{j}>0$. We refer to this as a "mixed" case. Firm $i$ 's reaction function derives directly from (3), whereas, readjusting (??), firm $j$ 's reaction function is given by

$$
p_{j 1}=\frac{A+c b+\pi_{2} / 2 \epsilon}{2 b}+\frac{1}{2 b} \frac{1}{2 \epsilon} K_{j}+\frac{d}{2 b} p_{i 1}
$$

From the two reaction functions it is easy to derive the following equilibrium prices of the two firms:

$$
\begin{aligned}
& \widehat{p}_{i 1}^{C}=\widehat{p}_{1}^{C}+\frac{d}{2 \epsilon\left(4 b^{2}-d^{2}\right)} K_{j}, \\
& \widehat{p}_{j 1}^{C}=\widehat{p}_{1}^{C}+\frac{b}{\epsilon\left(4 b^{2}-d^{2}\right)} K_{j} .
\end{aligned}
$$


Comparing these equilibrium prices to those obtained in the pure shareholder equilibrium in (4) and in the pure stakeholder equilibrium in Proposition 1, we obtain the following result.

Proposition 3 With marginal cost uncertainty, the equilibrium prices in a mixed equilibrium lie in between those obtained in the two pure cases with either only shareholder or stakeholder firms, i.e., $\widehat{p}_{1}^{C}<\widehat{p}_{i 1}^{C}<\widehat{p}_{j 1}^{C}<\widehat{p}_{1 K}^{C}$.

Turning next to the comparison of values in the mixed equilibrium, we substitute (13) and (14) into (2) and the corresponding expression for $V_{j}$, and obtain:

$$
\begin{aligned}
& \widehat{V}_{i S H A}^{C}\left(K_{j}\right)=\widehat{V}_{S H A}^{C}+\frac{b d}{(2 b+d)} \frac{\left[A-c(b-d)+\pi_{2} / 2 \epsilon\right]}{2 \epsilon(2 b-d)^{2}} K_{j}+\frac{b d^{2}}{4 \epsilon^{2}\left(4 b^{2}-d^{2}\right)^{2}} K_{j}^{2}, \\
& \widehat{V}_{j S T A}^{C}\left(K_{j}\right)=\widehat{V}_{S H A}^{C}+\frac{d^{2}}{(2 b-d)} \frac{\left[A-c(b-d)+\pi_{2} / 2 \epsilon\right]}{2 \epsilon(2 b-d)^{2}} K_{j}-\frac{b\left(2 b^{2}-d^{2}\right)}{2 \epsilon^{2}\left(4 b^{2}-d^{2}\right)^{2}} K_{j}^{2},
\end{aligned}
$$

where $\widehat{V}_{i S H A}^{C}\left(K_{j}\right)$ refers to the equilibrium value of shareholder firm $i$ competing against stakeholder firm $j$, while $\widehat{V}_{j S T A}^{C}\left(K_{j}\right)$ is the equilibrium value of stakeholder firm $j$ when competing against shareholder firm $i$. Unlike the pure cases analyzed above, the value of the shareholder firm depends now on the stakeholder orientation of the competing stakeholder firm, as represented by $K_{j}$. We can now state the following result.

Proposition 4 In a mixed equilibrium, with marginal cost uncertainty, the shareholder firm is always more valuable than the stakeholder firm.

The proposition follows from a simple comparison of (15) and (16) and is illustrated in Figure 2, where the value $\widehat{V}_{i S H A}^{C}\left(K_{j}\right)$ of the shareholder firm and the value $\widehat{V}_{j S T A}^{C}\left(K_{j}\right)$ of the stakeholder firm are plotted as a function of $K_{j}$. Since $b>d, \widehat{V}_{i S H A}^{C}\left(K_{j}\right)$ is convex while $\widehat{V}_{j S T A}^{C}\left(K_{j}\right)$ is concave in $K_{j}$. Both functions have positive slope at $K_{j}=0$, but, given that the slope of $\widehat{V}_{i S H A}^{C}\left(K_{j}\right)$ is greater than that of $\widehat{V}_{j S T A}^{C}\left(K_{j}\right)$, the shareholder firm is always more valuable than the stakeholder firm. The intuition for this result is fairly simple. Proposition 2 states that with marginal cost uncertainty having a stakeholder orientation can be beneficial 
to both firms due to the commitment to further soften competition. Proposition 4 goes one step further and establishes that the shareholder firm benefits more than the stakeholder firm from the softening of competition as it gets to free-ride on the increase in price arising out of firm $j$ 's stakeholder orientation.

Having analyzed the mixed equilibrium, we can now compare the payoffs to firms in this equilibrium against the two pure regimes, where both firms are either stakeholder or shareholder oriented.

Proposition 5 Suppose that firms face uncertainty concerning their marginal costs.

(a) The value $\widehat{V}_{S H A}^{C}$ of the pure shareholder firm is always less than the value $\widehat{V}_{i S H A}^{C}\left(K_{j}\right)$ of the mixed shareholder firm, and is less than the value $\widehat{V}_{j S T A}^{C}\left(K_{j}\right)$ of the mixed stakeholder firm for $0<K<K^{\dagger}$, where $K^{\dagger}$ satisfies $\widehat{V}_{S H A}^{C}=\widehat{V}_{j S T A}^{C}\left(K^{\dagger}\right)$.

(b) The value $\widehat{V}_{S T A}^{C}(K)$ of the pure stakeholder firm is always greater than the value $\widehat{V}_{j S T A}^{C}\left(K_{j}\right)$ of the mixed stakeholder firm, and is greater than the value $\widehat{V}_{i S H A}^{C}\left(K_{j}\right)$ of the mixed shareholder for $0<K<K^{\dagger \dagger}$, where $K^{\dagger \dagger}$ satisfies $\widehat{V}_{i S H A}^{C}\left(K^{\dagger \dagger}\right)=\widehat{V}_{S T A}^{C}\left(K^{\dagger \dagger}\right)$.

Part (a) of this proposition, which is illustrated in Figure 2, follows directly from inspection of (8), (15), and (16). The key features are as before the convexity of $\widehat{V}_{i S H A}\left(K_{j}\right)$, the concavity of $\widehat{V}_{j S T A}\left(K_{j}\right)$ and their positive slopes at $K_{j}=0$. The result that both firms can be better off in a mixed equilibrium relative to the case where they are both shareholder oriented again points to the importance of the commitment to soften competition that is embodied in firms' stakeholder-oriented governance structures when uncertainty about marginal costs is important. The result also implies that a shareholder firm would prefer to compete in a stakeholder-oriented market rather than one where shareholder focus is the norm, if it does not itself change its governance structure.

Part (b) of this proposition is likewise illustrated in Figure 2 and can be established from inspection of (9), (15), and (16). The results follow from the shape of the functions $\widehat{V}_{i S H A}^{C}\left(K_{j}\right), \widehat{V}_{j S T A}^{C}\left(K_{j}\right)$ and $\widehat{V}_{S T A}^{C}(K)$ and the sign of their slopes at $K_{j}=K=0$ in the usual 
way. ${ }^{7}$ The intuition for this part of Proposition 5 is similar to that in part (a): when firms are concerned about the uncertain realization of their marginal costs, credibly committing to soften competition is highly valuable. Since a stakeholder governance structure provides the greatest such commitment, stakeholder firms competing against other stakeholder firms reap the greatest benefit.

The analysis in this section has broad implications for the political economy of foreign entry, as well as for firms' governance practices abroad. We discuss these issues in more detail in Section 5.

\section{Extensions}

In this section we consider various extensions and robustness considerations. First, we generalize the cost structure to account for multiple sources of uncertainty. Then, we extend the analysis to consider firm financial constraints and bankruptcy, different continuation payoffs and firm exit considerations. Since the primary focus of the paper is to show that the interests of stakeholders and shareholders may be aligned in certain cases, we restrict the analysis to the case of cost uncertainty. We discuss the case of demand uncertainty only briefly in a few places.

\subsection{Shock structure}

In the analysis so far we have considered marginal cost uncertainty and demand uncertainty separately. Here we look at the case where both are present and we then consider the effect of an uncertain fixed cost.

Suppose the firm is subject to both the marginal cost shock $\widetilde{\epsilon}_{i}$ and the demand shock $\widetilde{\eta}_{i}$.

\footnotetext{
${ }^{7}$ Note that $\widehat{V}_{j S T A}\left(K_{j}\right)$ and $\widehat{V}_{S T A}(K)$ do not intersect for $K>0$. This can be shown by first noting that the coefficient of $K_{j}$ in (16) is smaller than the coefficient of $K$ in (9) since $b>0$. Moreover, from the comparison of the coefficients of $K_{j}^{2}$ and $K^{2}$, it can be seen that the absolute value of the coefficient in (16) is larger than the one in (9) if $2 b\left(2 b^{2}-d^{2}\right)>(b-d)(2 b+d)^{2}$. This condition is equivalent to $d^{3}+b d^{2}>0$, which is always satisfied since $d>0$.
} 
The firm's maximization problem can be written as

$$
\begin{aligned}
\max _{p_{i 1}} V_{i} & =E\left[\pi_{i 1}\right]+\operatorname{Pr}\left(\pi_{i 1} \geq 0\right) \pi_{2} \\
& =E\left[\pi_{i 1}\right]+\operatorname{Pr}\left(\left(p_{i 1}-c-\widetilde{\epsilon}_{i}\right)\left(A-b p_{i 1}+d p_{j 1}-\widetilde{\eta}_{i}\right) \geq 0\right) \pi_{2} .
\end{aligned}
$$

Substituting the expressions for $\operatorname{Pr}\left(A-b p_{i 1}+d p_{j 1} \geq \widetilde{\eta}_{i}\right)$ and $\operatorname{Pr}\left(\widetilde{\epsilon}_{i}<\left(p_{i 1}-c\right)\right)$ and using the fact that $\widetilde{\epsilon}_{i}$ and $\widetilde{\eta}_{i}$ are independent, we then have

$$
V_{i}=E\left[\pi_{i 1}\right]+\left(\frac{p_{i 1}-c+\epsilon}{2 \epsilon}\right)\left(\frac{A-b p_{i 1}+d p_{j 1}+\eta}{2 \eta}\right) \pi_{2}
$$

The first order condition yields

$$
\frac{\partial V_{i}}{\partial p_{i 1}}=\frac{\partial}{\partial p_{i 1}} E\left[\pi_{i 1}\right]+\frac{1}{4 \epsilon \eta} \pi_{2}\left(A-2 b p_{i 1}+d p_{j 1}+b c+\eta-b \epsilon\right)=0
$$

Whether this pushes the price up or down relative to the case with no uncertainty depends on the sign of the term $\eta-b \epsilon$. If $\eta<b \epsilon$, prices are pushed down and competition is increased. If $\eta>b \epsilon$, prices are pushed up and competition is softened.

Note that the first case, where $\eta<b \epsilon$, corresponds to the case where small increases in prices have a bigger effect on the likelihood that demand will be negative than that the price-cost margin will be positive. Conversely, the case where $\eta>b \epsilon$ corresponds to the case where price increases have a bigger effect on the likelihood of positive margins than on demand.

Suppose next that firms face uncertainty in that their fixed costs are subject to a random shock so first period profits are given by

$$
\pi_{i}=\left(p_{i 1}-c\right)\left(A-b p_{i}+d p_{j}\right)-\widetilde{F}_{i}
$$

where $\widetilde{F}_{i}=F+\widetilde{\theta}_{i}$ and $\widetilde{\theta}_{i}$ is uniformly distributed on $[-\theta, \theta]$ and, for simplicity, we normalize 
$F$ to 0 . The firm's maximization problem is

$$
\begin{aligned}
\max _{p_{i 1}} V_{i} & =E\left[\pi_{i 1}\right]+\operatorname{Pr}\left(\pi_{i 1} \geq 0\right) \pi_{2} \\
& =E\left[\pi_{i 1}\right]+\operatorname{Pr}\left(\left(p_{i 1}-c\right)\left(A-b p_{i 1}+d p_{j 1}\right)-\widetilde{\theta}_{i} \geq 0\right) \pi_{2} .
\end{aligned}
$$

Note, however, that $\operatorname{Pr}\left(\left(p_{i 1}-c\right)\left(A-b p_{i 1}+d p_{j 1}\right)-\widetilde{\theta}_{i} \geq 0\right)$ is maximized whenever $E\left[\pi_{i 1}\right]=$ $\left(p_{i 1}-c\right)\left(A-b p_{i 1}+d p_{j 1}\right)$ is maximized. Therefore, adding a shock to profits directly, or to the firm's fixed costs, has no effect on the price that firms choose in equilibrium.

\subsection{Financial constraints and bankruptcy}

So far we have assumed that firms exit when their profits in period 1 are negative. Here we provide a foundation for the bankruptcy condition by explicitly allowing firms to borrow at the beginning of their lives, with repament occuring at the end of period 1 , before initiating the second period project. Failure to repay the due debt payment triggers liquidation and forces the firm to exit the market, thus preventing it from operating in period 2. Firms may choose to borrow either because of strategic interaction considerations as in Brander and Lewis (1986) or Showalter (1996), or because they obtain a tax benefit through the tax deductibility of interest payments.

Specifically, consider the following modification of the model. Suppose that there is a period 0 at which the firm can choose how much to borrow, denoted by $D_{0}$. If the firm chooses to borrow in period 0 , it must repay the amount $D_{1}$ at the end of period 1 or else face bankruptcy and liquidation. For simplicity, assume that no additional borrowing is possible at the end of period 1, and that the debt cannot be rolled over. Firms pay taxes $\tau$ on their gross profits and, as is commonly the case, we assume that interest payments are tax deductible. The market for credit is competitive so that lenders are willing to provide credit as long as they break even in expectation. The rest of the model stays as before.

Given a promised debt repayment $D_{1}$, the firm will be able to meets it's obligations and 
avoid bankruptcy if

$$
\left[\pi_{1}-\left(D_{1}-D_{0}\right)\right](1-\tau)-D_{0} \geq 0
$$

The term $D_{1}-D_{0}$ represents the interest paid by the firm, which is tax deductible. Principal, $D_{0}$, is repaid after tax obligations have been met. Substituting for $\pi_{1}$, we can write this condition as

$$
\left[\left(p_{i 1}-c-\tilde{\epsilon}\right)\left(A-b p_{i 1}+d p_{j 1}\right)-\left(D_{1}-D_{0}\right)\right](1-\tau)-D_{0} \geq 0
$$

From this we see that, given prices $p_{i 1}$ and $p_{j 1}$, the firm will continue if $\tilde{\epsilon} \leq \widehat{\epsilon} \equiv p_{i 1}-c-$ $\frac{D_{1}-\left(D_{1}-D_{0}\right) \tau}{\left(A-b p_{i 1}+d p_{j 1}\right)(1-\tau)}$ and the probability of survival is then $\operatorname{Pr}(\tilde{\epsilon} \leq \widehat{\epsilon})$.

Given this, the total value of firm $i$ is

$$
V_{i}=\operatorname{Pr}(\tilde{\epsilon} \leq \widehat{\epsilon})\left[E\left[\pi_{i 1} \mid \tilde{\epsilon} \leq \widehat{\epsilon}\right](1-\tau)-D_{1}+\left(D_{1}-D_{0}\right) \tau+\pi_{2}(1-\tau)\right]
$$

and the objective of a firm with a stakeholder orientation $K_{i} \geq 0$ is to maximize

$$
\begin{aligned}
\max _{p_{i 1}} \Omega_{i} & =V_{i}+\operatorname{Pr}(\tilde{\epsilon} \leq \widehat{\epsilon}) K_{i} \\
& =\operatorname{Pr}(\tilde{\epsilon} \leq \widehat{\epsilon})\left[E\left[\pi_{i 1} \mid \tilde{\epsilon} \leq \widehat{\epsilon}\right](1-\tau)-D_{1}+\left(D_{1}-D_{0}\right) \tau+\pi_{2}(1-\tau)+K_{i}\right]
\end{aligned}
$$

The first order condition for maximization of $\Omega_{i}$ is

$$
\frac{\partial \Omega_{i}}{\partial p_{i 1}}=\int_{-\epsilon}^{\widehat{\epsilon}} \frac{\partial \pi_{i 1}}{\partial p_{i 1}}(1-\tau) f(\tilde{\epsilon}) d \tilde{\epsilon}+\frac{\partial \widehat{\epsilon}}{\partial p_{i 1}}\left(\pi_{2}(1-\tau)+K_{i}\right) f(\widehat{\epsilon})=0
$$

We denote the solution to (17) as $p_{i 1}^{*}$.

From (17) we can determine what the effect of a debt obligation, as measured by $D_{1}$, is on product market competition. This problem is similar to that studied in Showalter (1995), who shows that how debt affects equilibrium prices, $\frac{d p_{11}^{*}}{d D_{1}}$, depends on the sign of $\frac{\partial^{2} \Omega_{i}}{\partial D_{1} \partial p_{i 1}}$, as 
given by

$$
\frac{\partial^{2} \Omega_{i}}{\partial D_{1} \partial p_{i 1}}=\frac{\partial \widehat{\epsilon}}{\partial D_{1}}\left(\frac{\partial \pi_{i 1}}{\partial p_{i 1}}(1-\tau) f(\widehat{\epsilon})\right)+\frac{\partial^{2} \widehat{\epsilon}}{\partial D_{1} \partial p_{i 1}}\left(\pi_{2}(1-\tau)+K_{i}\right) f(\widehat{\epsilon})
$$

Algebraic manipulations show that this expression is negative, so that $\frac{d p_{i 1}^{*}}{d D_{1}}<0$. In other words, the prospect of having to repay the debt obligation $D_{1}$ reduces the price firm $i$ charges in the first period, making it more aggressive in the product market.

We can now determine the optimal amount of debt for firm $i$. Since the firm's owners obtain a cash flow of $D_{0}$ at period 0 in exchange for a promise to repay $D_{1}$ at the end of period 1, they solve the following problem:

$$
\max _{D_{1}} W_{i}=\Omega_{i}+D_{0}
$$

where

$$
D_{0}=\operatorname{Pr}(\tilde{\epsilon} \leq \widehat{\epsilon}) D_{1}+\operatorname{Pr}(\tilde{\epsilon}>\widehat{\epsilon}) E\left[\max \left\{\pi_{i 1}(1-\tau)+\left(D_{1}-D_{0}\right) \tau, \pi_{i 1}\right\} \mid \tilde{\epsilon}>\widehat{\epsilon}\right]
$$

Equation (18) represents the participation constraint of the investors providing the initial loan $D_{0}$. The first term is the expected repayment that they receive when the firm is solvent at the end of period 1 and honors the promised repayment $D_{1}$, which happens with probability $\operatorname{Pr}(\tilde{\epsilon} \leq \widehat{\epsilon})$. The second term is what the investors expect to obtain when the firm is insolvent at the end of period 1 , which occurs with probability $\operatorname{Pr}(\tilde{\epsilon}>\widehat{\epsilon})$. This is equal to the maximum between $\pi_{i 1}(1-\tau)+\left(D_{1}-D_{0}\right) \tau$ and $\pi_{i 1}$ depending on whether the firm is able to repay the interest $D_{1}-D_{0}$ to investors and benefit from the tax advantage before distributing the first period profits to investors.

The FOC to this problem can be written as

$$
\frac{d W_{i}}{d D_{1}}=\frac{\partial \Omega_{i}}{\partial D_{1}}+\frac{\partial D_{0}}{\partial D_{1}}+\frac{\partial \Omega_{i}}{\partial p_{i 1}} \frac{d p_{i 1}}{d D_{1}}+\frac{\partial D_{0}}{\partial p_{i 1}} \frac{d p_{i 1}}{d D_{1}}+\left(\frac{\partial \Omega_{i}}{\partial p_{j 1}} \frac{d p_{j 1}}{d D_{1}}+\frac{\partial D_{0}}{\partial p_{j 1}} \frac{d p_{j 1}}{d D_{1}}\right)
$$


The third term, $\frac{\partial \Omega_{i}}{\partial p_{i 1}} \frac{d p_{i 1}}{d D_{1}}$, is zero from the envelope theorem. The fourth term is negative given that $\frac{d p_{i 1}^{*}}{d D_{1}}<0$, as is the last term in brackets since it derives from the strategic interaction between firms. These terms show, as argued in Showalter (1995), that there is no strategic reason to issue debt with price competition and cost uncertainty, and that, in fact, both a profit maximizing as well as a shareholder oriented firm would want to be all equity financed. However, these terms are all small for values of $D_{1}$ close to 0 , and thus can be dominated by the first two terms in (19) if they are strictly positive.

To see this, it is useful to express the period 0 maximization problem explicitly as

$$
\max _{D_{1}} W_{i}=\int_{-\epsilon}^{\widehat{\epsilon}}\left(\pi_{i 1}(1-\tau)-D_{1}+\left(D_{1}-D_{0}\right) \tau+\pi_{2}(1-\tau)+K_{i}\right) f(z) d z+D_{0}
$$

where

$$
D_{0}=\int_{-\epsilon}^{\widehat{\epsilon}} D_{1} f(z) d z+\int_{\widehat{\epsilon}}^{\widehat{\widehat{\epsilon}}}\left(\pi_{i 1}(1-\tau)+\left(D_{1}-D_{0}\right) \tau\right) f(z) d z+\int_{\widehat{\widehat{\epsilon}}}^{\epsilon} \pi_{i 1} f(z) d z
$$

and $\widehat{\widehat{\epsilon}}=p_{i 1}-c-\frac{D_{1}-D_{0}}{A-b p_{i 1}+d p_{j 1}}$ is the threshold value of $\tilde{\epsilon}$ at which the first period profit is just enough for the firm to be able to repay the interests on debt, $D_{1}-D_{0}$. With this, one can show that

$$
\frac{\partial \Omega_{i}}{\partial D_{1}}+\frac{\partial D_{0}}{\partial D_{1}}=\tau F(\widehat{\hat{\epsilon}})-\frac{\pi_{2}(1-\tau)+K_{i}}{A-b p_{i 1}+d p_{j 1}} f(\widehat{\epsilon})
$$

From here, we note that, despite the fact that there is no strategic reason for issuing debt, a value maximizing firm (i.e., one for which $K_{i}=0$ ) may nevertheless find it beneficial to issue debt and face a payment $D_{1}>0$ at the end of the first period as a result of the tax deductibility of interest payments, reflected by the term $\tau F(\widehat{\hat{\epsilon}})$, as long as this benefit is large enough, i.e., for $\tau$ sufficiently large. However, it is also clear that the incentive to issue debt will be lower for stakeholder $\left(K_{i}>0\right)$ than for shareholder oriented firms $\left(K_{i}=0\right)$.

We can now establish two results based on the analysis in this section. First, as in the basic model without debt, the concern for other stakeholders beyond just shareholders makes 
the firm more conservative and leads to higher prices, thus softening competition. This can be established from (17). Second, stakeholder firms prefer to have a more conservative capital structure because of their greater concern for survival. Given that a stakeholder oriented firm competes less aggressively in the product market and has a more conservative capital structure, stakeholder oriented firms should be more likely to survive into the second period. Moreover, the effect through capital structure reinforces that through the stakeholder con-

cern: given that $D_{1}^{S T}<D_{1}^{S H}$ and $\frac{d p_{i 1}^{*}}{d D_{1}}<0$, stakeholder firms compete less aggressively both because of the direct effect of the concern for continuation on their pricing decisions as well as because of the indirect effect stemming from their more conservative capital structures.

Our implication on the optimal capital structure is in line with that in Maksimovic and Titman (1991) that firms hold lower debt as a way to credibly commit to providing better employee benefits; and with that in Berk et al. (2010) that firms issue only modest level of debt despite the presence of potentially large tax shields as a way to lower their probability of bankrutpcy and thus provide better risk sharing to their employees.

\subsection{Continuation profits}

In the analysis above, we have assumed that the firms' profits in the second period, $\pi_{2}$, are the same whether the firm has a stakeholder or a shareholder orientation. This is consistent with the fact that when there is no possibility of continuation, as must be the case in any final period, firms will simply attempt to maximize single period profits, irrespective of their governance structures. Nevertheless, during intermediate periods one may well expect that the firms' continuation values differ due to differences in their product market behaviors induced by their governance structures. To analyze this possibility, in this section we add an additional period to the model.

Specifically, we extend the model by adding a period 0 where each firm $i$ chooses its price $p_{i 0}$ to maximize the sum of period 0's profit plus the expected continuation value. Firms face the same marginal cost uncertainty in period 0 as in period 1 . The shock is 
independently distributed across the two periods. In the case of a shareholder oriented firm, the continuation value is simply it's market value. For a stakeholder oriented firm, the relevant continuation value includes the expected value associated with stakeholders' desire to continue operating, as described more fully below. The model is otherwise unchanged.

We solve by backward induction. Consider the period 1 problem. The firms' objective functions are identical to those studied above, in (2) and (7) for the shareholder and stakeholder oriented firms, respectively. The solutions, either $\widehat{p}_{1}^{C}$ or $\widehat{p}_{1 K}^{C}$, are therefore the same as before, with the implication that $\widehat{p}_{1}^{C}<\widehat{p}_{1 K}^{C}$ and that $\widehat{V}_{1, S H A}^{C}<\widehat{V}_{1, S T A}^{C}(K)$ for $K<K^{*}$ (the subscript 1 reflects the fact that these values correspond now to the firms' market values as of period 1).

Consider now the period 0 problem. A shareholder oriented firm maximizes

$$
\max _{p_{i 0}} V_{i 0}=E\left[\pi_{i 0}\right]+\operatorname{Pr}\left(\pi_{i 0} \geq 0\right) \widehat{V}_{1, S H A}^{C}
$$

By contrast, a stakeholder oriented firm maximizes

$$
\begin{aligned}
\max _{p_{i 0}} \Omega_{i} & =V_{i 0}+\operatorname{Pr}\left(\pi_{i 0} \geq 0\right)\left(\widehat{V}_{1, S T A}^{C}(K)+\operatorname{Pr}\left(\pi_{i 1} \geq 0\right) K\right)+\operatorname{Pr}\left(\pi_{i 0} \geq 0\right) K \\
& =V_{i 0}+\operatorname{Pr}\left(\pi_{i 0} \geq 0\right)\left(\widehat{V}_{1, S T A}^{C}(K)+\left(1+\operatorname{Pr}\left(\pi_{i 1} \geq 0\right)\right) K\right) .
\end{aligned}
$$

Note that, again, this problem is isomorphic to the first period problem studied above, replacing only the second period profit, $\pi_{2}$, by the respective continuation values, $\widehat{V}_{1, S H A}^{C}$ for the shareholder firms and $\widehat{V}_{1, S T A}^{C}(K)$ for the stakeholder firms. In addition, a stakeholder firm obtains a benefit $K$ if it survives from period 0 into period 1, separate from the benefit they receive for surviving from period 1 to period 2 .

Denote the solution to $(20)$ as $\widehat{p}_{0}^{C}$, and that to (21) as $\widehat{p}_{0 K}^{C}$. It is straightforward to see, from inspection of (20) and (21), that $\widehat{p}_{0}^{C}<\widehat{p}_{0 K}^{C}$ for $\widehat{V}_{1, S H A}^{C}<\widehat{V}_{1, S T A}^{C}(K)+\left(1+\operatorname{Pr}\left(\pi_{i 1} \geq 0\right)\right) K$, which is certainly true for $K<K^{*}$ and in fact will be true for a larger range of values for $K$. From this, we see that a stakeholder orientation may soften competition in period 0 for two 
reasons. First, as before, the benefit $K$ stakeholders obtain when the firm survives reduces the incentive to behave aggressively in the product market, and this benefit is compounded given that it is only obtained in the first period if the firm survives up to that point. Second, to the extent that the continuation market value (i.e., the expected market value at period 1) of the firm may be higher when it is a stakeholder firm, this gives an additional reason to be less aggressive in order to increase it's probability of survival and enjoy the higher market value. We can therefore conclude that, much as in the baseline two-period model, even with more periods and different continuation values depending on the governance structure, a stakeholder oriented firm will likely be less aggressive in the product market each period, and will in fact generate higher shareholder value in each period as long as its concern for survival, $K$, is not excessively high.

\subsection{Firm exit}

In this section, we consider the possibility that, in choosing their prices, firms have a strategic incentive associated with industry structure: by charging a lower price, one firm might be able to induce the exit of another, thus increasing its own profits in subsequent periods. Moreover, the incentives to engage in such "predatory" behavior may be different for stakeholder firms, which themselves are largely concerned with survival, than it is for shareholder firms, which only care about maximizing overall profitability.

Specifically, consider again the baseline two-period model, but suppose now that in the second period, firm $i$ 's profits are given by $\pi_{2}^{M}$ if firm $j$ fails (i.e., exits) after period 1, leaving firm $i$ as a monopolist in period 2, and $\pi_{2}^{D}<\pi_{2}^{M}$ if both firms survive. Given this, a shareholder firm maximizes

$$
\max _{p_{i 1}} V_{i}=E\left[\pi_{i 1}\right]+\operatorname{Pr}\left(\pi_{i 1} \geq 0\right)\left[\left(1-\operatorname{Pr}\left(\pi_{j 1} \geq 0\right)\right) \pi_{2}^{M}+\operatorname{Pr}\left(\pi_{j 1} \geq 0\right) \pi_{2}^{D}\right]
$$


while a stakeholder firm's problem is to maximize

$$
\left.\max _{p_{i 1}} \Omega_{i}=V_{i}+\operatorname{Pr}\left(\pi_{i 1} \geq 0\right)\right) K
$$

To find the equilibrium prices we differentiate (22) and (23) with respect to the price. The problem is similar to that in the basic model except for the fact that the concern for survival introduces now an element of strategic substitutability. If firm $j$ follows firm $i$ and also increases its own price, both firms have a higher probability of survival and will be more likely to obtain $\pi_{2}^{D}$ instead of $\pi_{2}^{M}$ in the second period. This provides an incentive for firm $i$ to deviate and reduce its own price. In order to prevent this deviation from being profitable, we need, as in the basic model, that $\frac{\partial^{2} V_{i}}{\partial p_{i 1} \partial p_{j 1}} \geq 0$. This conditions boils down to

$$
\frac{\partial_{i}^{2} V_{i}}{\partial p_{i 1} \partial p_{j 1}}=d-\frac{\left(\pi_{2}^{M}-\pi_{2}^{D}\right)}{4 \epsilon^{2}} \equiv G \geq 0
$$

and thus to a restriction on the difference $\pi_{2}^{M}-\pi_{2}^{D}$ so that the positive effect of a higher first-period price by firm $j$ on firm $i$ 's first-period profit dominates the negative effect that a higher probability of survival of firm $j$ has on firm $i$ 's second-period profit.

Given this, the equilibrium prices with marginal cost uncertainty are

$$
\widehat{p}_{1}=\frac{A+c b+\frac{1}{4 \epsilon^{2}}\left[(\epsilon+c) \pi_{2}^{M}+(\epsilon-c) \pi_{2}^{D}\right]}{2 b-G}
$$

for a shareholder firm, and

$$
\widehat{p}_{1 K}=\widehat{p}_{1}+\frac{1}{4 b \epsilon}\left(\frac{2 b}{2 b-G}\right) K
$$

for a stakeholder firm.

It can be seen immediately that, as usual, $\frac{\partial \widehat{p}_{1 K}}{\partial K}>0$, so that a concern for stakeholders serves to soften competition by increasing prices and reducing quantity in the first period. This implies that the results of the basic model remain valid when exit is explicitly taken into account. A similar result obtains for the comparison of firm value. 


\section{$5 \quad$ Empirical predictions}

The main insight of this paper is that governance arrangements in the form of stakeholder or shareholder orientation affect firms' competitive behavior and outcomes in the product market and, as a consequence, firm value. Concerning the former, the model predicts that the effect of having a stakeholder orientation depends on the type of shocks to which firms are subject. To the extent that the shock structure differs across industries, the model predicts that a concern for stakeholders should lead to higher prices as a way to boost survival in industries that primarily face marginal cost uncertainties and to lower prices in industries that are more subject to demand uncertainties. These predictions are novel and have not been tested empirically yet. One way of doing so would be to proxy cost and demand uncertainties with the variability of annual growth in costs and sales, respectively. The prediction would then be that stakeholder orientation should lead to a softening of competition in industries where costs are more variable and to a toughening of competition in industries where sales are more variable.

Following from this, our model predicts that stakeholder orientation, as long as it is not excessive, should lead to higher overall firm value in industries that primarily face marginal cost uncertainties and always to lower firm value in industries characterized by demand uncertainties. Although the mechanism behind this cross-industry prediction has not been tested empirically yet, it is worth pointing out that manufacturing industries are much more important in stakeholder oriented countries like Germany and Japan, while services are more predominant in shareholder oriented countries like the US. To the extent that cost uncertainty is relatively more important than demand uncertainty in manufacturing compared to services, this admittedly very stylized observation is suggestive of our implication that stakeholder governance is more beneficial in industries where cost uncertainty prevails. Consistent with these observations, Fauver and Fuerst (2006) and Ginglinger et al. (2009) find that employee representation in the board increases firm value, as measured by Tobin's Q or profitability, in Germany and France, respectively. Similarly, Hillman and Keim (2001) 
and Claessens and Ueda (2008) find that a larger stakeholder orientation in the form of stakeholder management or employment protection improves efficiency and firms' values.

Even when potentially profitable, the benefit of being stakeholder oriented firms vanishes in our model if the concern for stakeholders becomes excessive. To the extent that the size of $K$ in our model can be, for example, interpreted as the number of employee representatives on the board, this prediction is consistent with the findings in Gorton and Schmid (2004) that German companies having equal representation by employees and shareholders trade at a market discount compared to companies with one-third of employee representation; and those in Fauver and Fuerst (2006) of diminishing returns to employee representation over the level of one-third of board seats. Similar results are also obtained by Ginglinger et al. (2009) for the case of France. ${ }^{8}$

Our analysis focuses on the effect of competition in the product market as the channel through which stakeholder governance affects firm value. For this channel to work, firms must actually compete strategically in the market. This is captured in our model by the parameter $d$, which measures the degree of substitutability between the firms' products and which we require to be positive. While we are not aware of any formal test of this specific channel, indirect evidence can be found in the empirical finding in Cremers, Nair and Peyer (2008) that stakeholders improve firm efficiency in industries that are competitive, but not when they are monopolistic.

The model has also implications for the effects of globalization that allows for competition between stakeholder and shareholder firms. The analysis implies that, when stakeholder orientation is beneficial, as is the case in industries where cost uncertainty prevails, the presence of shareholder firms in stakeholder societies should lead to tougher competition in

\footnotetext{
${ }^{8}$ The effects of stakeholder governance on firm value share some similarities with the empirical evidence on the effects of Employ Share Ownership Plans (ESOPs). Some papers (e.g., Chapilinsky and Niehaus, 1994, Jones and Kato, 1995, and Beatty, 1995) find that ESOPs can be value increasing, while others (e.g., Kim and Ouimet, 2008) suggest that the positive effect vanishes for large ESOPs. To the extent that ESOPs can be interpreted as a form of stakeholder orientation, these results are in line with our predictions. However, whereas the effect of ESOPS on firm value works through workers' incentives, stakeholder governance works in our model through the channel of product market competition.
} 
that prices should be lower than in the case where only stakeholder firms would be present. In terms of firm value, this result implies that shareholder firms benefit most from globalization as they can free-ride on stakeholder competitors and increase their value relative to the case where they compete only with other shareholder firms. By contrast, stakeholder firms have lower firm value when competing with shareholder firms than when competing with other stakeholder firms only. However, stakeholder firms should remain more valuable than shareholder firms with globalization, as long as their concern for stakeholders is not too excessive.

One interesting implication of these results concerns the political economy of foreign entry. As long as a stakeholder orientation creates value, firms focusing only on shareholder value should have strong incentives to enter into a stakeholder-oriented economy through the acquisition of an incumbent firm as this increases their value. However, as long as they maintain their corporate structure as in their home country, shareholder firms are likely to encounter greater resistance when entering a stakeholder-oriented market through a takeover than would firms that are more stakeholder friendly, since the entry of the former is more detrimental to incumbent firms. In contrast, shareholder-oriented economies should not be protectionist towards the entry through acquisition by stakeholder firms as their presence should have a positive effect on the incumbent firms. To the extent that our simple analysis can be used to analyze foreign economic policy, these results are consistent with the casual observation that shareholder-oriented countries like the US tend to be less protectionist and more open to foreign industry penetration than more stakeholder-oriented countries like Japan. This is in line with the empirical results found in Lawrence (1991) and Weinstein and Yafeh (1995) that entry in Japan is difficult.

Finally, our model suggests that firm orientation is related to its capital structure. It predicts that, because of the greater concern for survival, stakeholder firms should have a more conservative capital structure in terms of lower levels of debt. These results are consistent with the findings in Verwijmeren and Derwall (2010) that firms that take into 
account the costs for employees stemming from the firm's bankruptcy operate with lower debt ratios to reduce the probability of bankruptcy; and with the findings in Bae et al. (2011) that firms with higher employee friendly ratings maintain low debt ratios.

\section{Concluding Remarks}

Most of the literature on corporate governance is concerned with ensuring that the firm is operated in the interests of shareholders. However, in many countries firms are required by law or social norms to be not only concerned with shareholders but also with other stakeholders such as employees and suppliers. In this paper we have developed a model of mandated stakeholder capitalism and have compared the shareholder and stakeholder equilibria. We have also considered the situation resulting from globalization where stakeholder and shareholder firms compete and have identified the circumstances where each type of firm does better.

Our approach suggests a number of directions for future research. One of the interesting questions is why some countries adopt stakeholder governance while others do not, and why governments adopt such governance although it may benefit firms and employees at the expense of consumers. There is a growing literature on corporate governance and political economy that emphasizes that the political process plays a very important part in determining the corporate governance structure in a country (see, e.g., Hellwig, 2000; Roe, 2003; Rajan and Zingales 2003, 2004; Pagano and Volpin 2005a, 2005b: Perotti and von Thadden, 2006; and Perotti and Volpin, 2007). For example, if workers and shareholders are made better off by co-determination and consumers are made worse off, then it is still likely that co-determination will be implemented. The reason is that workers and shareholders are usually better organized and are in a position to lobby in favor of co-determination, whereas consumers are dispersed. Such a political economy approach can help shed light on the emergence of stakeholder governance. 
Our focus is on the effects of stakeholder orientation on product market competition and firm value. An interesting issue is whether there are alternative contractual mechanisms that may allow shareholder firms to achieve the same commitment as stakeholder firms. One example is managerial incentives. The question is whether they can be an alternative to stakeholder governance and if so, whether they are crowded out once firms are forced to adopt stakeholder concerns. A deeper analysis of these issue is certainly an interesting future research question.

The model we have used for the product market is very simple. Many other features could be added. In particular, we have not considered many of the factors that make stakeholder governance socially costly. One example is the difficulties that this system creates for firing workers and reallocating resources. Also, we have treated shareholders, stakeholders, and consumers as different groups. In practice, of course, there is a large overlap between them and this may affect the desirability of stakeholder governance. Lastly, we have considered the case where continuation is always efficient since second-period profits are always positive. If this was not the case, a strong concern for firm survival as implied by a stakeholder orientation could lead to inefficient continuation and reduce firm value. 


\section{References}

Acharya, V., S. Myers, and R. Rajan, 2011, "The Internal Governance of Firms," Journal of Finance, 66, 689-720.

Allen, F., 2000, "Capital Structure and Imperfect Competition in Product Markets," in P. Hammond and G. Myles (eds.), Incentives, Organization, and Public Economics: Papers in Honour of Sir James Mirrlees, Oxford: Oxford University Press, 281-301.

Allen, F., 2005, "Corporate Governance in Emerging Markets," Oxford Review of Economic Policy 21, 164-177.

Allen, F., E. Carletti, and R. Marquez (2008). "Stakeholder Capitalism, Corporate Governance and Firm Value," Working Paper 07-39, Wharton Financial Institutions Center, University of Pennsylvania.

Allen, F., and D. Gale, 2000, Comparing Financial Systems, Cambridge, MA: MIT Press.

Aggarwal, R. and A. Samwick, 1999, "Executive Compensation, Strategic Competition and Relative Performance Evaluation; Theory and Evidence," Journal of Finance 54, 19992043.

Bae, K.-H., J.-K. Kang and J. Wang, 2011, "Employee Treatment and Firm Leverage: A Test of the Stakeholder Theory of Capital Structure," Journal of Financial Economics, 100, $130-155$.

Beatty, C.A., 1995, "The Cash Flow and Informational Effects of Employee Stock Ownership Plans," Journal of Financial Economics, 38, 211-240.

Becht, M., P. Bolton, and A. Röell, 2003, "Corporate Governance and Control," Chapter 1 in G. Constantinides, M. Harris, and R. Stulz, (eds.) the Handbook of the Economics of Finance, Amsterdam: Elsevier-North-Holland, 1-109.

Berk, J.B., R. Stanton and J. Zechner, 2010, "Human Capital, Bankruptcy, and Capital Structure," Journal of Finance, 65(3), 891-926.

Blinder, A., 1993, "A Simple Note on the Japanese Firm," Journal of the Japanese and International Economies 7, 238-255. 
Brander, J. and T. Lewis, 1986, "Oligopoly and Financial Structure: The Limited Liability Effect," American Economic Review 76, 956-970.

Brealey, R., S. Myers and F. Allen, 2011, Principles of Corporate Finance, 10th edition, New York: McGraw Hill.

Campbell, Jr., R. and C. Frost, 2007, "Managers' Fiduciary Duties in Financially Distressed Companies: Chaos in Delaware (and Elsewhere)," Journal of Corporation Law 32, 491-525.

Cespa, G. and G. Cestone, 2007, "Corporate Social Responsibility and Managerial Entrenchment," Journal of Economics and Management Strategy, 16(3), 741-771.

Chaplinsky, S. and G.R. Niehaus, 1994, "The Role of ESOPs in Takeover Contests," Journal of Finance, 49,1451-70.

Claessens, S., and K. Ueda, 2008, "Banks and Labor as Stakeholders: Impact on Economic Performance," IMF Working Paper 08/229, Washington, D.C.

Cremers, M., V. Nair, and U. Peyer, 2008, "Takeover Defenses and Competition: The Role of Stakeholders," Journal of Empirical Legal Studies 5, 791-818.

Dasgupta, S. and S. Titman, 1998, "Pricing Strategy and Financial Policy," Review of Financial Studies 11, 705-737.

Demsetz, H., 1983, "The Structure of Ownership and the Theory of the Firm," Journal of Law and Economics, 26(2), 375-390.

Denis, D., and J. McConnell, 2003, "International Corporate Governance," Journal of Financial and Quantitative Analysis 38, 1-36.

Dixit, A., 1986, "Comparative Statics for Oligopoly," International Economic Review 27, $107-122$

Dore, R., 2000, Stock Market Capitalism: Welfare Capitalism: Japan and Germany Versus the Anglo-Saxons, Oxford: Oxford University Press.

Fauver, L. and M. Fuerst, 2006, "Does Good Corporate Governance Include Employee Representation? Evidence from German Corporate Boards," Journal of Financial Eco- 
nomics $82,673-710$.

Fershtman, C. and K. L. Judd, 1987, "Equilibrium Incentives in Oligopoly," American Economic Review 77, 927-940.

Ginglinger, E., W. Megginson, and T. Waxin, 2009, "Employee Ownership, Board Representation, and Corporate Financial Policies," working paper, University of Oklahoma.

Gorton, G. and F. Schmid, 2004. "Capital, Labor, and the Firm: A Study of German Codetermination," Journal of the European Economic Association 2, 863-905

Hellwig, M., 2000, "On the Economics and Politics of Corporate Finance and Corporate Control," Chapter 3 in X. Vives (ed.), Corporate Governance: Theoretical and Empirical Perspectives, Cambridge, UK: Cambridge University Press, 95-134.

Hillman, A. and G. Keim, 2001, "Shareholder Value, Stakeholder Management, and Social Issues: What's The Bottom Line?", Strategic Management Journal 22, 125:139.

Jackson, G. and H. Miyajima, 2007, "Introduction: The Diversity and Change of Corporate Governance in Japan," Chapter 1 in M. Aoki, G. Jackson, and H. Miyajima, (eds.), Corporate Governance in Japan: Institutional Change and Organizational Diversity, Oxford: Oxford University Press.

Jensen, M. and W. Meckling, 1976, "Theory of the Firm: Managerial Behavior, Agency Costs and Ownership Structure," Journal of Financial Economics 3, 305-360.

Jensen, M., 2001, "Value Maximization, Stakeholder Theory, and the Corporate Objective Function," Journal of Applied Corporate Finance 14, 8-21.

Jones, D.C. and T. Kato, 1995,"The Productivity Effects of Employee Stock-Ownership Plans and Bonuses: Evidence from Japan," American Economic Review, 85, 391-414.

Kim, E.H. and P. Ouimet, 2008, "Employee Capitalism or Corporate Socialism? Broadbased Employee Stock Ownership," unpublished manuscript, March.

Lawrence, R. 1991, "Efficient of Exclusionist? The Import Behavior of Japanese Corporate Groups," Brookings Papers on Economic Activity, 1, 311-338.

Magill, M., M. Quinzii, and J-C. Rochet (2011). "Reforming Capitalism," working paper, 
University of California, Davis.

Maksimovic, V. and S. Titman, 1991, "Financial Policy and Reputation for Product Quality," Review of Financial Studies, 4, 175-200.

Milhaupt, C., 2001, "Creative Norm Destruction: The Evolution of Nonlegal Rules in Japanese Corporate Governance," University of Pennsylvania Law Review 149, 2083-2129.

Pagano, M. and P. Volpin, 2005a, "The Political Economy of Corporate Governance," American Economic Review 95, 1005-1030.

Pagano, M. and P. Volpin, 2005b, "Managers, Workers, and Corporate Control," Journal of Finance 60, 843-870.

Perotti, E. and P. Volpin, 2007,"Politics, Investor Protection and Competition," working paper.

Perotti, E. and E. von Thadden, 2006, "The Political Economy of Corporate Control and Labor Rents," Journal of Political Economy 114, 145-174.

Rajan R. and L. Zingales, 2003, "The Great Reversals: The Politics of Financial Development in the Twentieth Century," Journal of Financial Economics 69, 5-50.

Rajan R. and L. Zingales, 2004, Saving Capitalism from the Capitalists: Unleashing the Power of Financial Markets to Create Wealth and Spread Opportunity, Princeton: Princeton University Press.

Rieckers, O. and G. Spindler, 2004, "Corporate Governance: Legal Aspects," Chapter 11 in J. Krahnen and R. Schmidt (eds.), The German Financial System, Oxford: Oxford University Press, 350-385.

Roe, M., 2003, Political Determinants of Corporate Governance, Oxford: Oxford University Press.

Schmidt, R., 2004, "Corporate Governance in Germany: An Economic Perspective," Chapter 12 in J. Krahnen and R. Schmidt (eds.), The German Financial System, Oxford: Oxford University Press, 386-424.

Scott, K., 1998, "The Role of Corporate Governance in South Korean Economic Reform," 
Journal of Applied Corporate Finance 10, 8-15.

Shleifer, A. and R. Vishny, 1997, "A Survey of Corporate Governance," Journal of Finance 52, 737-783.

Showalter, D.M., 1995, "Oligopoly and Financial Structure: Comment," American Economic Review, 647-653.

Sklivas, S., 1987, "The Strategic Choice of Managerial Incentives," RAND Journal of Economics 18, 452-458.

Tirole, J., 2001, "Corporate Governance," Econometrica 69, 1-35.

Tirole, J., 2006, The Theory of Corporate Finance, Cambridge, MA:MIT Press.

Verwijmeren, P. and J. Derwall, 2010, "Employee Well-being, Firm Leverage, and Bankruptcy Risk," Journal of Banking and Finance, 34, 956-964.

Wang, B. and H. Huang, 2006, "China's New Company Law and Securities Law: An Overview and Assessment," Australian Journal of Corporate Law 19, 229-242.

Weinstein, D.E. and Y. Yafeh, 1995, “Japan's Corporate Groups: Collusive or Competitive? An Empirical Investigation of Keiretsu Behavior," Journal of Industrial Economics, 43(4), 359-376.

Wymeersch, E., 1998, “A Status Report on Corporate Governance Rules and Practices in Some Continental European States," in K. Hopt, H. Kanda, M. Roe, E. Wymeersch, and S. Prigge (eds.), Comparative Corporate Governance: The State of the Art and Emerging Research, Oxford: Clarendon Press.

Yoshimori, M., 1995, "Whose Company Is It? The Concept of the Corporation in Japan and the West," Long Range Planning 28, 33-44. 


\section{Figure 1: Whose Company Is It?}

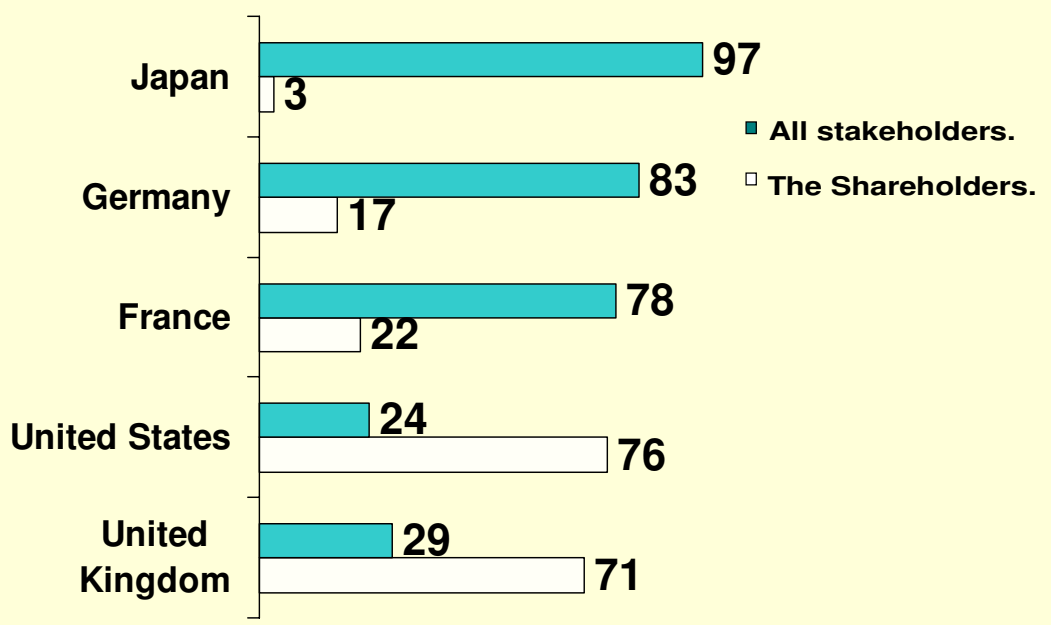

Number of firms surveyed: Japan, 68; United States, 82; United Kingdom, 78; Germany, 100; France, 50.

Source: Masaru Yoshimori, "Whose Company Is It? The Concept of the Corporation in Japan and the West." Long Range Planning, Vol. 28, No. 4, pp. 33-44, 1995 
Figure 2: Firm value in the pure and mixed equilibrium with marginal cost uncertainty. The figure depicts the value of a firm in a pure shareholder equilibrium $\left(\widehat{V}_{S H A}^{C}\right)$, a firm in a pure stakeholder equilibrium $\left(\widehat{V}_{S T A}^{C}(K)\right)$, and a shareholder firm $\left(\widehat{V}_{i S H A}^{C}(K)\right)$ and stakeholder firm $\left(\widehat{V}_{j S T A}^{C}(K)\right)$ in a mixed equilibrium as a function of the concern for stakeholders $K$ in the case of marginal cost uncertainty. While $\widehat{V}_{S H A}^{C}$ is independent of $K, \widehat{V}_{S T A}^{C}(K)$ is initially increasing in $K$ and is decreasing for larger $K$. This implies that $\widehat{V}_{S T A}^{C}(K)$ is greater than $\widehat{V}_{S H A}^{C}$ for $K<$ $K^{*}$. For the mixed case, $\widehat{V}_{i S H A}^{C}(K)$ is always increasing in the other firm's stakeholder orientation, $K$. By contrast, $\hat{V}_{j S T A}^{C}(K)$ is first increasing for low values of $K$, but is then decreasing. However, $\hat{V}_{j S T A}^{C}(K)$ is always less than $\widehat{V}_{i S H A}^{C}(K)$. In the comparison of pure and mixed equilibria, a pure stakeholder firm is most valuable for $K<K^{++}$, while a mixed shareholder firm is most valuable otherwise.

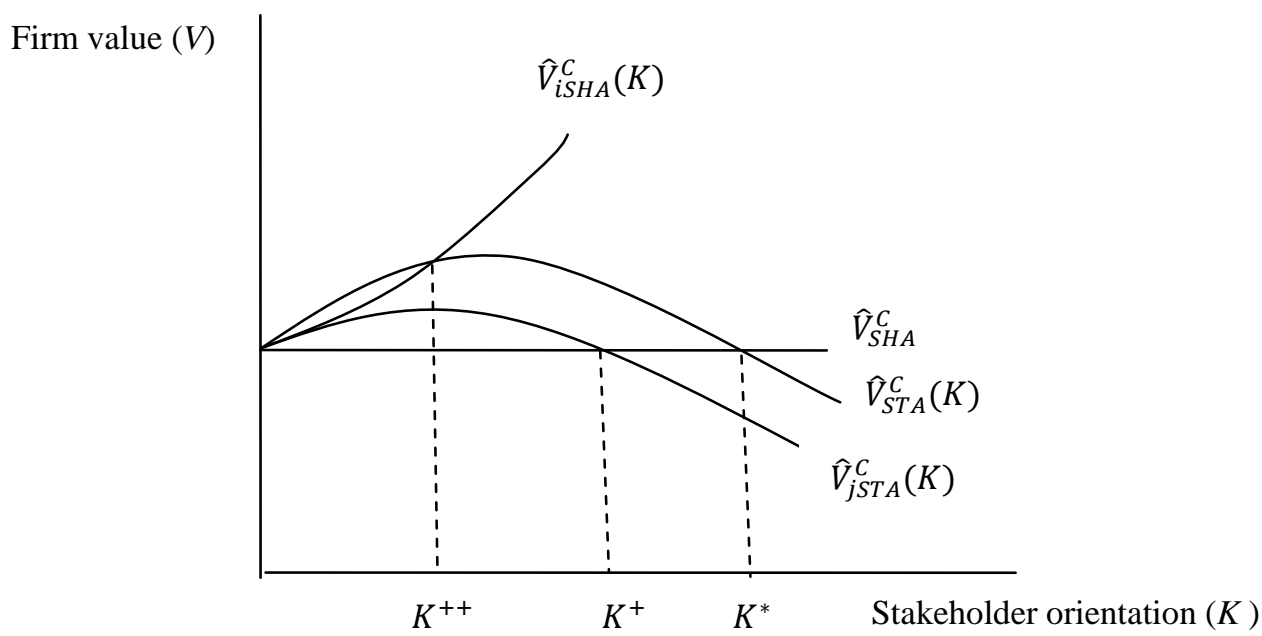


Table 1: Default probabilites for firms in US, Germany, France and Japan. The table reports the probability of individual firm default using the BlackScholes-Merton model employing data on all publicly-listed firms between 1990 and 2008 for the US, Germany, France and Japan as available in Datastream. To assess the difference in firm default probability between US and German, French and Japanese firms, respectively, a Welch diffferencein-country-means t-test assuming unequal variances is employed. ${ }^{* * *}$ Significant at $1 \%,{ }^{* *}$ significant at $5 \%,{ }^{*}$ significant at $10 \%$.

\begin{tabular}{|c|c|c|c|c|c|c|}
\hline \multicolumn{7}{|c|}{ Probability of Default } \\
\hline \multirow{2}{*}{\multicolumn{2}{|c|}{ Number of Observations }} & \multirow{3}{*}{$\frac{\text { Mean }}{10.4}$} & \multirow{2}{*}{$\begin{array}{l}\text { Standard } \\
\text { Deviation }\end{array}$} & \multirow{2}{*}{$\begin{array}{l}\text { Difference with US } \\
\text { Probability of Default }\end{array}$} & \multirow{3}{*}{ Welch's t-test } & \multirow{2}{*}{$\begin{array}{c}\text { Significance } \\
\text { Level }\end{array}$} \\
\hline & & & & & & \\
\hline US & 55,477 & & 24.5 & - & & - \\
\hline Germany & 4,201 & 6.6 & 19.5 & -3.9 & 12.1 & $* * *$ \\
\hline France & 4,731 & 4.9 & 16.5 & -5.5 & 21.2 & $* * *$ \\
\hline Japan & 28,049 & 3.0 & 10.2 & -7.4 & 61.7 & $* * *$ \\
\hline
\end{tabular}

